\title{
Effectiveness of Teaching Economics in Higher Secondary School Level, Nepal
}

\author{
Chakra Bahadur Khadka, PhD.
}

Faculty of Economics, Tribhuvan University, Patan Multiple Campus, Nepal

\begin{abstract}
Teaching economics to students in a clear and unbiased manner supports beginner students, master the essential principles of understanding the economizing problem, specific economic issues, help the student to understand and apply economics in a precise and empirical manner on economic issues and promote a lasting student interest in issue of economics. The objective of this paper is to analyze the effectiveness of teaching economics in higher secondary school level. Two hundred four teachers and equal students' number have been selected for questionnaire survey. The survey data were collected from different training centers of the training and workshop interval. Psychometric scale, was designed for data collection. For the data analysis, SEM is used, including simultaneously complete tests of model fit, together with simultaneously overall tests of model fit, specific parameter estimates, compare simultaneously, OLS coefficients, Means and Variances. The finding is based on the assumption that is; default model is correct, the probability of getting a discrepancy as significant as 73.59 is 0.00 of students' understanding of economics in their classroom. Maximum likelihood estimates at all the parameter estimates are highly significant. If EFET positive change by 1, T_EFET_2 also positively change by 0.88 . The regression weights to estimate, 0.88 , has a standard error of about 0.06. Dividing the regression weight estimate by the estimate of its standard error gives $z=0.88 / 0.06=14.91$. The variables of student understanding are significantly different from 0 except S_QOAT_4. As ATME positive changes by 1, S_ATME_2 also positively change 0.57. The regression weights to estimate, 0.57, has a standard error of about 0.04 . Students they agreed with $8 \mathrm{~A}$ and $9 \mathrm{~A}$ statement. This is recommended that teach the teachers as a workshop style and training in improving economics instruction in Higher Secondary Schools Level. The experimental program helps teachers to gain an understanding of economic concepts and improve pedagogy. Improved classroom environment, the latest text materials might be the encouraging to economics subject to the student.
\end{abstract}

Key words: Teaching economics, Deductive, Training, Text Materials, Structural Equation Modeling.

\section{INTRODUCTION}

Economics is one of a precise subject taught in the higher secondary school level. It is important to both students and the civilization as great for the reason that it wounds transversely all compasses of human effort as it can be understood in its simplest 
definition by Robbins (1935), “...thus economics as a science which studies human behavior as a relationship between ends and scarce means which have alternative uses...." By this definition, Robbins (1935) lay emphasis on economics as a science and that economic investigation would be based on positive and logical method rather than normative with vague judgments. The important ideas of teaching and learning economics in classroom are to help the basic stage of student masters the principles vital for understanding the financial problem, precise economic issues. The policy alternatives, help to the students understanding, then apply the economic perspective also reason accurately and empirically with economic matters. This promotes a lasting student interest in economics and the economy (McConnell, Brue, \& Flynn, 2009). British philosopher of positive science andeconomists John Neville Keynes (1890) who was the father of renowned economists J. M. Keynes; salvaged that "learning about economics, both inductive and deductive logical were required to understand how the economy functions" (p. 44, 100). Moreover, John Neville Keynes (1890) divided economics into three parts; positive economics, normative economics, and applied economics. The science and art of economics relating the lessons learned in positive economics to the normative goals determined in normative economics. In generally means that the objective of applied economics is to find how to come from positive science to normative economics.

According to the National Council of Educational Research and Training, India (NCERT, 2005) "the answer to the question; why economics is taught in schools is not only essential in answering students but also for the teachers when they teach economics in schools. Teachers are likely to understand why economics is taught so that they can plan the classroom activities effectively". The details of opinions would also help in understanding the content topics and subtopics and why they are included in the curricular contents. The aims at teaching economics at the higher secondary stage are: making students understand some basic economic concepts and developing economic reasoning and thus learners can apply to their daily life as citizens, workers and consumers; enable learners to realize their role in country building and sensitize them to the economic issues that the nation is facing today, to equip learners with the basic tools of economics basic tools of economics and statistics to analyze economic issues. This is pertinent to even those who may not pursue this course, this course of the higher secondary stage; and to develop an understanding among students that there can be more than one view on any economic issue and to develop the skills to argue logically with reasoning (NCERT, 2005).

Additionally, NCERT, (2005) emphasize "if all competitors in the global economy are to achieve a better quality of life for their populations, there must be economic cooperation between all countries. This does not mean that developed countries must 
control the purposes of less-developed countries. Instead, it means sharing concepts across cultures, against a context of economic theories, ideas awareness." To achieve this understanding, students must be taught to consider economic theories, ideas and activities from the points of view of changed individuals, nations and cultures in the world economy. Although broad knowledge is impossible, students can exploration for understanding through a wide range of different aspects of the global economy. Their exploration may inspire a lifelong interest in the promotion of international level understanding.

Capable teacher prepares a perspective planfor the entire academic year, where the entire syllabus is looking into and a term wise plan of different units is prepared. This can clear confusion created when the concerned teacher is absent and another one takes over. Also, it leads to transparency and coordination among the group of teachers, teaching different sections. Besides the overall plan, each unit and content area need to be structured with regard to the objectives, content coverage, methodology, specific learning activities and so on, as laid down in the basic components of a Teaching Unit. Let us briefly discuss each component of a teaching unit (Robertson \& Acklam, 2000; Chibueze, 2014).

In the word of O'Sullivan and Sheffrin (2003), "when we set "out to write an economics text, we were driven by the vision of the sleeping student." The book, Macroeconomics Principles and Tools written by O'Sullivan and Sheffrin (2003) they wrote in preface ... "A few years before, one of the authors was in the internal of a fascinating lecture on monopoly pricing when he heard snoring. It wasn't the first time a student had fallen asleep in one of his classes, but this was the loudest snoring, he had ever heard it sounded like a sputtering chainsaw. The instructor turned to Bill, who was sitting next to the sleeping student and asked.... Could you wake him up?" "Bill looked at the sleeping student and the gazed theoretically around the room at the other students." He finally looked back at the professor and said, "well professor, I think you should wake him up. After all, you put him to sleep...." The occurrence altered the economics teacher of teaching economics. It highlighted for basic truth about many students, economics isn't precisely exciting. The teacher assumed the challenge to get first-time economics students to see the relevance to economics to their lives, their careers, and their futures (O'Sullivan \& Sheffrin, 2003).

Economics is a subject that involves observation and collection of data and in such a subject the role of the teacher becomes even more important. Teaching economics with charts, diagrams, equations from as an integral part of teaching and these things can be used properly only under the guidance of a teacher. In the Nepalese scenario, economics teachers of higher secondary school level have to act as the major source of 
knowledge of the subject matter as a role model to the students and facilitator to solve various other raised by the students.For the teaching of economics, it is necessary to have direct observation of the environment and physical conditions. Students have to be encouraged for observing things by them and to have a proper assessment and knowledge of the subject matter. Only a good teacher of economics can provide such type of encouragement. An economics teacher can accomplish this task successfully if $\mathrm{s} /$ he can guide the student in a scientific and thorough manner.

Training com workshops were organized by the Higher Secondary Education Board (HSEB), Nepal for economics teachers. The HSEB was the authorized body to plan, implement and evaluate programs related to higher secondary level. Authority was also accountable for giving training for the subject teachers. Contents of training included, curriculum framework, teaching, learning materials, classroom pedagogy and testing principle, and comprises the fundamentals of pedagogy, the latest concepts of classroom realities, learner-centered class, planning, materials adaptation and use, test items' construction and assessment and many other issues. The objectives of the study are to examine the effectiveness of teaching economics in higher secondary school level factors that influences teaching economics to the teachers, and evaluate the degree of interest and attitudes of students which influences learning economics in higher secondary level.

\section{REVIEW OF LITERATURE}

A study report submitted to national teachers' institute Ebonyi State University study center by Chibueze in (2014) set the objective of identifying the factors influencing the effectiveness of teaching and learning of economics in higher secondary schools in the Izzi local government zone. The investigative design of the research was descriptive and questionnaire survey. Total population of the study was ten thousand, nine hundred students. Likewise, seventy-five teachers in the senior secondary schools have been used. One hundred and fifty teachers and students were sampled in five selected schools. The descriptive statistics were used to analyze the data. The findings showed that teaching and learning of economics in our secondary schools are affected by unqualified economics teachers, poor method of teaching, inadequate instructional materials and attitudes and interest of the teachers and students. Based on the findings some recommendations were made thus Employment of economics teachers by the government through the ministry of education should be strictly based on merit so as to make it possible for only those who studied the course to be appointed.

A research paper was published by Adu, Galloway and Olaoye (2014) regarding the teachers' characteristics and students' attitude towards economics in secondary schools. The study samples involved in six hundred and forty students selected through cluster 
sampling and simple random sampling techniques. To test the hypotheses of the study Pearson product moment correlation and t-statistics were used. The finding of the study shows that, students perceive their teachers' in terms of knowledge of contents of economics, communication ability, teaching methods and classroom management skills has a significant relationship with the students' attitude towards economics. When the students' perception of their teachers' characteristics is low, hence the students' attitude to economics tends to be negative.

Likewise, a research was completed by Idoko and Emmanuel (2015) about teachers' effectiveness in teaching economics. Teachers, as the pillars of an education system are expected to be resourceful as a strategy for effecting teaching in Nigerian schools and colleges. Structured questionnaire made up of ten items was constructed in an Ankpa local government area of Kogi State and administered the questionnaire to one hundred students and ten teachers in fifty secondary schools. A Likert weighted mean average of four-point rating scale was employed for the analysis of the data. The result shows that teacher's strategies and methods of teaching economics in the secondary schools in the study area was inadequate due to lower educational qualification, lack of motivation in terms of remuneration and fringe benefit, the lack of teacher's recognition and cognitive experience. Employment of teachers, especially in economics should be based on assessment through written test and classroom teaching to guide against the influx of quacks into the teaching profession, and government interventions to ensure that right method of teaching employed should supervise teachers regularly and make sure that right method should be adopted in teaching and learning process were the recommendations made by author.

A survey was conducted by Blazar (2015) into education production function that moved away from narrative teacher inputs, such as education, certification, and salary, directing as a replacement of on observational measures of teaching practice. Build on this conversation by exploiting within-school, between grade, and crosscohort variation in scores from two observation instruments; further, the condition with a uniquely rich set of teacher characteristics, practices, and skills. The findings of the study indicated that inquiry-oriented instruction positively predicts student achievement. Content errors and imprecision were negatively related, though the estimates and were sensitive to the set of 'covariates' included in the model. Two other dimensions of instruction, classroom emotional support and classroom organization, were not related to this outcome. Findings recommended that recruitment and development efforts aimed at improve the quality of the teacher workforce.

A study by Izci (2016) was concerned about supporting learning assessment forms, an important part of instruction in internal and external factors affecting teachers' adoption of 
formative assessment. The objective was to support learning is known as formative assessment and itcontributes student's learning gain and motivation. Thestudy, was completed byusinga teacher's change environment framework, reviews literature on formative assessment and presents atentative model that illustrates the factors impacting the teachers' adoption of formative assessment in their teaching. There were four main factors consisting personal, contextual, resource-related and external factors that in fluenced teachers' practices of formative assessment were the significant conclusions of the study.

Research articles in economics across the curriculum to the integration of economic concepts into various disciplines were surveyed by Smirnova in (2016). The main objective of the study was, to help high school teachers gain a deeper understanding of various economic concepts, and demonstrate active engagement as well as other collaborative instructional strategies. Fiveday in-residence training com workshop covered three topics was included, the topic was money and inflation, business cycles and unemployment, and government and the economy. Twentytwo teachers attended the program in 2014, and seventeen teachers attended the program in 2015. The research contributes to the literature on economic education by describing the development of a multi-day program of the American Institute for Economic Research that uses the Economics-Across-the-Curriculum approach. The program focused on economics teachers and give importance of English language, arts, social studies, math, and foreign languages. The participants' diversity created cross-pollination of ideas, dynamism, and an interdisciplinary method of teaching. The integration of economic concepts into various subjects helps students develop critical thinking, information of text analysis, real-world application, and other skills that are transferable to various fields of study, academia, and the workplace. The paper showcases several lessons that were field-tested by participants in their classrooms after the completion of the program. The idea might serve as catalysts for other innovative ideas about integration of economics across the high school curriculum.

A research was accomplished by Vasiliki, Panagiota, and Maria (2016) about a new teaching method for teaching economics in secondary education. The aim of the study was to find out the attitudes and perceptions of students, when implementing this teaching process and to explore the extent to which this method can contribute to the improvement of teaching and learning. The authors evaluated an interdisciplinary approach to teaching economics through an innovative teaching method, in the context of the Greek Senior High School. The important findings of the study were, the use of art and especially the use of a movie, helped students understand the basic concepts of the Stock Market. Furthermore, the use of audiovisual material facilitated the active participation in students and made the course more interesting. As a result, the class climate was friendlier enhancing the freedom of expression. The role-playing was a significant factor of formatting this climate and it created positive experiences of students. The new teaching methodology contributed to the enforcement of knowledge results which helped 
students to shape their own views of the economic issues related to the Stock Market and to develop an overall view of economic science in relation to real life.

A training manual for economics teachers, was published by Higher Secondary Education Board (HSEB) Nepal (2006). The main objective of the training manual in the Nepalese context of higher secondary level economics teacher was to make it as the major source of knowledge of the subject and assist instructors to act as a role model to the students and a facilitator to solve various other issues raised by the students. Whereas teaching economics, it is necessary to have direct observation of the environment and physical conditions. Students have to be encouraged for observing things by them and to have a proper assessment and knowledge of the subject matter. Only a good teacher of Economics can provide such type of encouragement. An economics teacher can accomplish this task successfully if he can guide the students in a scientific and systematic manner.

\section{DATA AND METHODOLOGY}

\section{a) Statistical Framework}

\section{i) Structural Equation Modeling}

Structural equation modeling (SEM) is a very general, predominantly linear, mostly crosssectional statistical modeling technique. Factor analysis, path analysis and regression represent special cases of SEM. SEM is a largely confirmatory, rather than exploratory, technique, that is, a researcher is more likely to use SEM to determine whether a certain model is valid, rather than using SEM to find a suitable model although. SEM is a quantitative research technique that can also incorporate qualitative methods. The model is used to show the causal relationships between variables. The relationships shown in SEM represent the hypotheses of the researchers. SEM produces data onto a visual display and this is part of its appeal. SEM is designed to look at the complex relationships between variables, and to reduce the relationships to visual representations. A research design can be described in terms of the design structure and the measurements that are conducted in the research. These structural and measurement relationships are the basis for a hypothesis for this study. SEM is a cross-sectional statistical modeling technique that has its origins in econometric analysis (Byrne, 2001).

SEM is a combination of factor analysis and multiple regression. The term factor and variable referred to the same concept in statistics. Path analysis is a variation of SEM, which is a type of multivariate procedure that allows a researcher to examine the independent variables and dependent variables in a research design. Variables can be continuous or discrete. SEM also works with measured variables and latent variables. Path analysis uses measured values only. Measured variables can be observed and are measurable. Latent variables cannot 
be observed directly, but their values can be implied by their relationships to observed variables (Loehlin, 1992; Kline, 2005).

Likewise, other two famous measures model known as the Non-Normed Fit Index (NNFI) or Tucker-Lewis Index (TLI), (Tucker \& Lewis, 1973) and Normed Fit Index (NFI) introduced by Bentler and Bonett (1980). NFI, proportion in the improvement of the overall fit of the hypothesized model compared to the independence model, in theory 0 measure poor fit and 1 measures perfect fit, measured acceptable when the statistical value of NFI is greater than .90 . NNFI, also similar to NFI but adjusts for model complexity, theoretically 0 means poor fit and 1 is perfect fit, considered satisfactory when it is greater than .90 . Nevertheless, these are fairly rales of thumbing (Bollen\& Joreskog, 1985).

A relative modem approach to model fit is to accept that models are only approximations, and that perfect fit may be too much to ask for. Instead, the problem is to assess how well a given model approximates the true model. This view led to the development of an index called for Root Mean Square Error of Approximation (RMSEA). If the approximation is good, the RMSEA should be small. Typically, an RMSEA of less than 0.00 is required, and statistical tests or confidence intervals can be computed to test if the RMSEA is significantly larger than this lower bound (Hox \& Bechger, 2011).

Structural equation modeling incorporates several approaches or frameworks to representing these models. In one well-known framework popularized by Joreskog and Sorbom (1982) in University of Uppsala. The general structural equation model can be represented by three matrix equations:

$$
\begin{aligned}
& \eta_{(m \times 1)}=B_{(m \times m)} \times \eta_{(m \times 1)}+\Gamma_{(m \times n)} \times \boldsymbol{\xi}_{(n \times 1)}+\boldsymbol{\xi}_{(m \times 1)} \\
& Y_{(p \times 1)}=\Lambda_{y(p \times m)} \times \eta_{(m \times 1)}+\boldsymbol{\varepsilon}_{(p \times 1)} \\
& X_{(q \times 1)}=\Lambda_{(q \times n)} \times \boldsymbol{\xi}_{(n \times 1)}+\Gamma \boldsymbol{\delta}_{(q \times 1)}
\end{aligned}
$$

Where, $\mathrm{B}_{(\mathrm{m} \times \mathrm{m}) \text { and }} \Gamma_{(\mathrm{m} \times \mathrm{n})}$ are coefficient and parameters and $\zeta$ is a random vector of effects of residuals. $y=p \times 1$ column vector of endogenous observed variables (y's); $\mathbf{x}=q \times 1$ column vector of exogenous observed variables (x's). Error of the vector measurement in $\mathrm{x}$ and $\mathrm{y}$ denoted by $\varepsilon=\mathrm{p} \times 1$ and $\delta=\mathrm{q} \times 1$. $\eta$ is a latent, endogenous variable. The regression matrix of $\mathrm{y}$ on $\eta$ is $\Lambda(\mathrm{x} \times \mathrm{y}) . \Lambda_{\mathrm{y}}=\mathrm{p} \times \mathrm{m}$ weight matrix representing paths from endogenous latent variables $(\eta)$ to observed y variables $\Lambda_{\mathrm{x}}=\mathrm{q} \times \mathrm{n}$ weight matrix representing paths from exogenous latent variables $(\xi)$ to observed $x$ variables, $\eta=\mathrm{m} \times 1$ vector of endogenous latent variables, $\xi=\mathrm{n} \times$ 1 vector of exogenous latent variables. 
In applied work, structural equation models are most often represented graphically. Figure 1 shows the interconnections among variables of a structural equation model.

Figure 1: Graphical Example of a Structural Equation Model

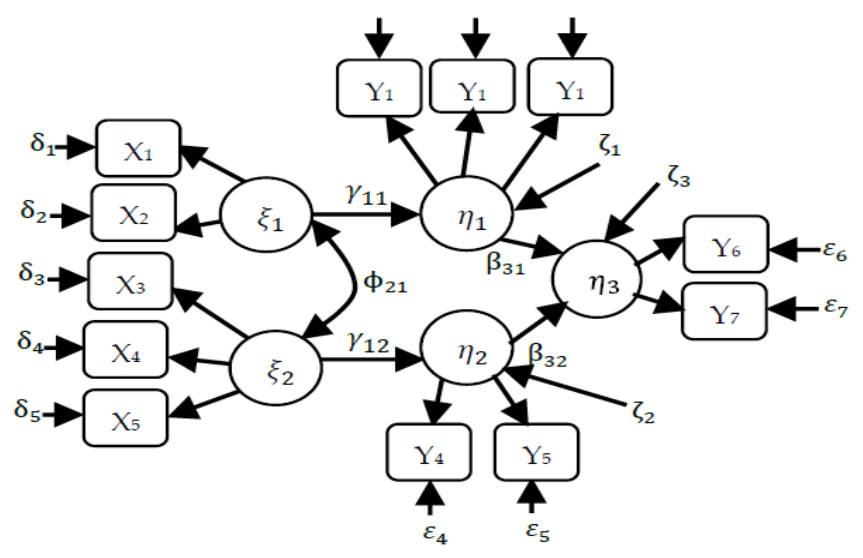

Graphical example of a structural equation model is presented In Figure 1. In structural equation modeling, the key variables of interest are usually latent constructs. All variables are indicated by the Greek character. Exogenous constructs are $\xi$. Endogenous constructs are indicated $\eta$. the structural model parameters representing regression relations between latent constructs $\gamma$ regression of an endogenous construct on an exogenous construct, or with the $\beta$. Parameters labeled with the $\phi$ represent these covariances. This covariance comes from common predictors of the exogenous constructs which lie outside the model under consideration. Structural error term, labeled with the $\zeta$. Manifest variables associated with exogenous constructs are labeled $X$, while those associated with endogenous constructs are labeled $Y$. The loadings linking constructs to measures are labeled with the $\lambda$. Structural equation models can include two separate $\lambda$ matrices, one on the $X$ side and one on the $Y$ side. Measurement error terms associated with $\mathrm{X}$ measures are labeled with the $\delta$ while terms associated with Y measures are labeled with $\varepsilon$. Theoretically, almost every measure has an associated error term.

\section{ii) Cronbach Coefficient Alpha}

The Cronbach Coefficient Alpha (Cronbach, 1951) is the truly familiar estimate of internal consistency of items in a model or survey Reliability and its Item Analysis. C-alpha is not a statistical test, but a coefficient of reliability based on the correlation between individual indicators. That is, if the correlation is high, then there is evidence that the individual indicators are measuring the same underlying construct. Therefore, a high c-alpha, or equivalently a high "reliability", indicates that the individual indicators measure the latent innovation well (European Commission, 2008). Cronbach's Coefficient Alpha can be defined as: 


$$
\alpha_{c}=\left(\frac{Q}{Q-1}\right) \frac{\sum_{i=j} \operatorname{COV}\left(x_{i}, x_{j}\right.}{\operatorname{Var}\left(x_{0}\right)}\left(\frac{Q}{Q-1}\right) 1-\left(\frac{\sum_{j} \operatorname{Var}\left(x_{j}\right.}{\operatorname{Var}\left(x_{0}\right)}\right)_{c}=1, . ., M, . i, j=1, . ., Q
$$

where, $\mathrm{M}$ indicates the number of countries considered, $\mathrm{Q}$ the number of individual indicators available, and $x_{0}=\sum_{q=1}^{Q} x j$ is the sum of all individual indicators. C-alpha measures the portion of the total variability of the sample of individual indicators due to the correlation between indicators. It increases to the number of individual indicators and with the covariance of each pair. If no correlation exists and individual indicators are independent, then $\mathrm{C}$-alpha is equal to zero, while if individual indicators are perfectly correlated, $\mathrm{C}$-alpha is equal to one.

\section{b) Data Collection}

The training for economics teachers was organized by HSEB in Gajuri, Dhading training center. At the center, 32 teachers were participated in different schools of the central development region. Likewise, Surkhet, training center, and 32 teachers were participated from different schools of from Midwest development region. Another was Palpa training center, and 42 teachers from different school of Midwest development region were participated, likewise in Damauli, training center, participant teachers were 35 from different schools of the western development region. In the Dhulikhel training center, participants were 33 from different schools of the central development region, lastly; Bardibas training center, participant were 30 teachers from different schools of the eastern development region.

Data were collected during the training period with economics teachers. Altogether 204 economics teachers were participating in different training/workshop center of different region of Nepal. The data also collected from higher secondary school level students in different region, area of training centers in different point of time. Two hundred four students were selected for questionnaire survey. A quota sampling technique has been used for data collection process, and students were from different public and private higher secondary schools. The questionnaire was designed into psychometric scale, and respondents specify their seven-point level of agreement or disagreement on a symmetric agree-disagree scale for some sequences of statements. Thus, the range captures the intensity of their feelings for a given item.

\section{c) Model Specification and Estimation of Parameters}

SEM is used as a statistical tool for data analyzed. The significance of SEM in this research is to examine the structural relationships between endogenous and exogenous variables, and the measurement model showing the relations between latent variables and their indicators. The statistics similarly used to identify the combination of factor analysis and multiple regression analysis, and to analyze the structural relationship between measured variables and latent constructs. Employing SEM to Specify pathways in the model, assuming the relationships of free pathways, in which hypothesized causal relationships between variables are tested. The parameter estimation is finalized by comparing the actual covariance matrices representing the relationships between variables and the estimated covariance matrices of the best fitting model. This is obtained through numerical maximization of a fit criterion as provided by maximum likelihood estimation, estimates mean, variances and squared multiple correlations, parameters, 
and general least squares methods. This is often undertaken by using a specialized SEM analysis program, of which various occur. A generalized least squares estimation and maximum likelihood estimation was developed Kullback and Leibler (1951). Following estimation equation is 'scale-free' least squares estimation (SLs) used for data analysis:

$f_{S L S}\left(\sum^{(g)} ; S^{(g)}\right)=\frac{1}{2} \operatorname{tr}\left[D^{(g)-1}\left(S^{(g)}-\Sigma^{(g)}\right)\right]^{2}$

Where, $\mathrm{D}^{(\mathrm{g})}=\operatorname{diag}\left(\mathrm{S}^{(\mathrm{g})}\right)$

Maximum likelihood estimation is the additional estimation equation presented as:

$$
\begin{aligned}
& f\left(\Sigma^{(g)} ; S^{(g)}\right)=\frac{1}{2} \operatorname{tr}\left[K^{(g)-1}\left(S^{(g)}-\Sigma^{(g)}\right)\right]^{2} \\
& \text { with, } K^{(g)}=(\hat{y} M L)
\end{aligned}
$$

where $\hat{\mathrm{Y}}_{\mathrm{ML}}$ is the maximum likelihood estimation of $\mathrm{Y}$.

Likewise, a distribution-free method also used in this research. The expectations of using this method, is likely optimal results of the discrepancy function measured correctly without any assumption of the distribution of variables (Joreskog \& Sorbom, 1982). This is the ideal situation introduced into covariance structure analysis by the asymptotically distributionfree (ADF) method of Browne (1984) and the minimum distance method of Chamberlain (1982), which is identical:

$C(\alpha, a)=[N-r]\left[\frac{\sum_{g}^{G}=1 N^{(g)} f\left(\mu^{(g)}, \sum^{(g)}, \bar{X}^{(g)}, S^{(g)}\right.}{N}\right][N-r] F(\alpha, a)$

\section{RESULT AND DISCUSSION}

\section{a) Reliability and Validity Test}

Cronbach's Alpha $(\alpha)$ used to measure the model exceeded 0.90, indicating excellent level of internal consistency. The value of Cronbach's Alpha Based on Standardized Items respective structures on this research model both cases (first case is 0.93 and, second case is 0.92) exceeded 0.92, thus the value indicating excellent internal consistency, which specifies that about 92.30 percent data are reliable and valid, therefore only 7.70 data are error.

\section{b) Model Test}

With regard to the goodness of fit issue, Measures of Minimum Discrepancy for Chi Square-Based is presented in Table 1. 
Table 1: Model Fits of the Cross-Validation

\begin{tabular}{|c|c|c|c|c|c|c|}
\hline \multirow{3}{*}{$\begin{array}{l}\text { Internal \& } \\
\text { External Factors } \\
\text { of Economics } \\
\text { Teachers }\end{array}$} & Model & NPAR & CMIN & DF & $\mathbf{P}$ & CMIN/DF \\
\hline & Default model & 21 & 1086.502 & 34 & .00 & 31.96 \\
\hline & Saturated model & 55 & .00 & 0 & & \\
\hline \multirow{4}{*}{$\begin{array}{l}\text { Understanding of } \\
\text { Economics }\end{array}$} & Independence model & 10 & 2761.62 & 45 & .00 & 61.36 \\
\hline & Default model & 21 & 673.59 & 34 & .00 & 19.81 \\
\hline & Saturated model & 55 & .00 & 0 & & \\
\hline & Independence model & 10 & 2233.49 & 45 & .00 & 49.63 \\
\hline
\end{tabular}

The presented value of Chi Square-Based Measures of Minimum Discrepancy assumption is that the default model is correct, the probability of getting a discrepancy as large as 1086.50 is 0.00 in first set of internal and external factors of teachers teaching economics. And another assumption is that the default model is correct, the probability of getting a discrepancy as large as 673.54 is 0.00 of students' understanding of economics in their classroom.

Table 2: Model Test

\begin{tabular}{llllccccccc}
\hline $\begin{array}{l}\text { Internal \& } \\
\text { External }\end{array}$ & Model & NFI & RFI & IFI & TLI & CFI & GFI & RMR & PCLOSE & RMSEA \\
\cline { 2 - 5 } & & & & & & & & & & \\
\cline { 2 - 9 } $\begin{array}{l}\text { Economics } \\
\text { Teachers }\end{array}$ & Default model & .82 & .74 & .82 & .76 & .82 & .80 & .27 & .00 & 0.03 \\
& Saturated & 1.00 & & 1.00 & & 1.00 & 1.00 & .00 & .00 & \\
& Independence & .00 & .00 & .00 & .00 & .00 & .22 & .78 & & 0.04 \\
$\begin{array}{l}\text { Understanding } \\
\text { of Economics } \\
\text { in Classroom }\end{array}$ & Default model & .92 & .83 & .92 & .75 & .92 & .87 & .10 & .00 & 0.02 \\
& Saturated & 1.00 & & 1.00 & & 1.00 & 1.00 & .00 & .00 & \\
& Independence & .00 & .00 & .00 & .000 & .00 & .25 & .50 & & 0.03 \\
\hline
\end{tabular}

These measures attempt to contrast some baselines models (not always a null hypothesis model) after another measurement model. The Baseline Comparisons of model are presented in Table 2 with different measurement values. The values of NFI influence of understanding level is 0.92 which indicates acceptable model fit and the value of NFI Internal \& External Factors of Teachers is 0.82 this value is less than 0.9 but more liberal cutoff of 0.80 . The value of RFI in both conditions close to 1 which is 0.74 and 0.83 , and the value indicates a good fit of the model. Likewise, IFI value is 0.82 and.92 and it is equal to or greater than 0.90 that indicates accept the model IFI value 
close to 1 indicates a good fit. IFI can be greater than 1 under certain circumstances. IFI is not recommended for routine use. TLI value is 0.76 and 0.75 in both conditions, and this value is close to 0.90 , this indicates an acceptable level of model fit. The value of CFI $>0.90$ or close to 0.95 indicates good fit, by convention, the CFI should be equal to or greater than 0.90 to accept the model. The result shows the value of CFI in both conditions is 0.82 and 0.92 , the value indicates a good fit of the model. GFI value is 0.80 and 0.87 in two conditions. The value is close to 1 , this means that it is a good fit of the model. The RMR standard model is 0.00 in both observation and this value indicated exact fit. The output data onto PCLOSE and RMSEA in both observations are 0.00 , the figure indicates exact fit of the model.

\section{c) Demographics}

Fundamental attributes including economics teachers' experience, and student's identity of class eleven and twelve, demographics is presenting: Among the valid samples $\left(\mathrm{N}_{1}=204, \mathrm{~N}_{2}=204\right.$, Total $\left.\mathrm{N}=408\right)$. In a survey, the numbers of men and women were dissimilar in $\mathrm{N}_{1}$ sample number that indicates men were $93 \%$, and women were $7 \%$; in $\mathrm{N}_{2}$ sample number $36.3 \%$ students were men and, $63.7 \%$ women. In addition, $81 \%$ respondents were younger aged 30 and above between 45 years aged, about $13 \%$ respondents were aged 46 years and older. Moreover, $78 \%$ respondents had teaching experiences more than 5 years. In computation, about $6 \%$ respondents had 20 years teaching experiences. Similarly, 92\% respondents were working in public school and had a permanent job, and, $8 \%$ respondents were working in private school and they had no permanent job, they were working as part-time and contract job. Among them, $76 \%$ respondents were working more than one school, whereas, $24 \%$ respondents were working their own school only. Similarly, $94 \%$ respondents were younger aged 19 to 23 years and $6 \%$ respondents were aged above 24 years and older. $50 \%$ respondents were studying class 11 and $50 \%$ class 12 . Finally, regarding respondent of $\mathrm{N}_{2^{\prime}}, 86.6 \%$ were enrolled in public school, and $13.4 \%$ enrolled in private school.

\section{d) Descriptive Statistics}

The internal and external appearances are the influencing factors in the economics. To identify the influencing factors of the economics teacher psychometric scale, was designed and descriptive statistics are presented of the respondents specify their level of agreement or disagreement in Table 3. 
Table 3: Descriptive Statistics of Effectiveness of Teaching Economics

\begin{tabular}{llcccc}
\hline $\mathbf{N}$ & Variables & Mean & Mean \% & Mode & Std. Dev. \\
\hline 1I & $\begin{array}{l}\text { Leading of economics teachers is MA economics } \\
\text { degree holders. }\end{array}$ & 6.20 & 88.57 & 7 & 1.17 \\
2I $\quad \begin{array}{l}\text { Teachers' insufficient qualification influences to } \\
\text { poor performance of students in economics. }\end{array}$ & 6.30 & 90.00 & 7 & 1.17 \\
3I $\quad \begin{array}{l}\text { Teachers' uncaring, attitudes to teaching of } \\
\text { economics affect the student's performance. }\end{array}$ & 6.11 & 87.29 & 7 & 1.09 \\
4I $\quad \begin{array}{l}\text { Lack of good teaching method affects students' } \\
\text { performance in economics }\end{array}$ & 6.13 & 87.57 & 7 & 1.13 \\
5I $\quad \begin{array}{l}\text { The deductive teaching method is chosen than } \\
\text { inductive method of teaching economics. }\end{array}$ & 5.11 & 73.00 & 5 & 1.45 \\
6E $\quad \begin{array}{l}\text { Nonexistence of classroom space affects the } \\
\text { teaching of economics. }\end{array}$ & 5.57 & 79.57 & 6 & 1.17 \\
7E $\quad \begin{array}{l}\text { Given time affects to the teaching of economics } \\
\text { teachers' preparation. }\end{array}$ & 5.94 & 84.86 & 7 & 1.34 \\
8E $\quad \begin{array}{l}\text { Lack of economics textbooks affect student } \\
\text { learning of economics. }\end{array}$ & 5.89 & 84.14 & 6 & 1.25 \\
9E $\quad \begin{array}{l}\text { Some schools do not even have libraries and this } \\
\text { contributes to ineffective teaching. }\end{array}$ & 6.76 & 96.57 & 7 & .74 \\
10E $\begin{array}{l}\text { Training for teacher in economics improving } \\
\text { teachers' qualities and better teaching economics in } \\
\text { the classroom. }\end{array}$ & 6.01 & 85.86 & 7 & 1.24 \\
\hline
\end{tabular}

There are ten statements and statements were divided into two groups internal and external factor that influencing teaching economics in classroom for higher secondary school level. From internal factor, the percentage of the mean value of the seven-point scale are a minimum of $73 \%$ and maximum of $90 \%$, and only one mode value is 5 and all points, mode value is 7 . About $85.3 \%$ on average respondents were totally agreed with the statements and only 14.7 data are error. The average percentage of mean valve means that teachers' insufficient qualification uncaring, attitudes to teaching, lack of good teaching method and chosen of logical methods of teaching influences to poor performance of students and this affects students' performance in economics subject.

The additional set of statement was external factor that influencing teaching economics in classroom for higher secondary level. According to the descriptive statistics in this group, the mode value is 7 for three questions and for two questions mode value is 6. Minimum percentage of mean values is 79.57 and maximum of $96.57 \%$. According to the maximum percentage of the mean value about $97 \%$ teachers agreed with 
the statements. Which indicates some schools does not even have libraries and this contributes to ineffective teaching economics. The average mean percentage is about $86.2 \%$, this data indicates $86.2 \%$ respondents were totally agreed with all statements and only 13.8 data are error.

Table 4: Maximum Likelihood Estimates: Regression Weights

\begin{tabular}{|c|c|c|c|c|c|c|c|c|}
\hline & & & Estimate & S.E. & C.R. & $P$ & Label & $\begin{array}{l}\text { Standardized } \\
\text { Regression } \\
\text { Weights: } \\
\text { Estimate }\end{array}$ \\
\hline T_EFET_1 & $<-$ & EFET & 1.00 & & & & & .84 \\
\hline T_EFET_2 & $<-$ & EFET & .88 & .059 & 14.90 & $* * *$ & par_1 & .80 \\
\hline T_EFET_3 & $<-$ & EFET & .53 & .034 & 15.69 & $* * *$ & par_2 & .82 \\
\hline T_EFET_4 & $<-$ & EFET & .39 & .085 & 4.59 & $* * *$ & par_3 & .30 \\
\hline T_EFET_5 & $<-$ & EFET & .39 & .062 & 6.40 & $* * *$ & par_4 & .41 \\
\hline T_IFET_1 & $<-$ & IFET & 1.00 & & & & & .92 \\
\hline T_IFET_2 & $<-$ & IFET & .78 & .057 & 13.74 & $* * *$ & par_5 & .73 \\
\hline T_IFET_3 & $<-$ & IFET & .83 & .051 & 16.46 & $* * *$ & par_6 & .80 \\
\hline T_IFET_4 & $<-$ & IFET & 1.07 & .042 & 25.38 & $* * *$ & par_7 & .93 \\
\hline T_IFET_5 & $<-$ & IFET & .93 & .047 & 20.04 & $* * *$ & par_8 & .87 \\
\hline
\end{tabular}

Maximum likelihood estimates of at all the parameter estimates are highly significant. In other words, all variables are significantly different from 0 . The interpretations of the parameter estimate are straight forward. When EFET goes up by 1, T_EFET_2 goes up by 0.88 . The regression weights to estimate, 0.88 , has a standard error of about .059. Dividing the regression weight estimate by the estimate of its standard error gives $\mathrm{z}=0.882 / .059=14.908$. This indicates that, the regression weight estimate is 14.91 standard errors above zero. When IFET goes up by 1 , T_IFET_5 goes up by $0.93 \%$. The regression coefficient of EFET_1 and T_EFET_1 positive and statistically significant at $99 \%$ confidence level. When IFET goes up by 1, T_IFET_4 goes up by 1.071 . When EFET goes up by 1, T_EFET_4 goes up by 0.391 . When EFET goes up by 1 standard deviation, T_EFET_1 goes up by 0.849 standard deviations. When IFET goes up by 1 , standard deviation T_IFET_4 goes up by 0.939 standard deviations. The probability of getting a critical ratio as large as 14.908 in absolute value is less than 0.001 . The value indicates, the regression weight for EFET in the prediction of T_EFET_2 is significantly different from zero at the 0.001 level (two-tailed). It is estimated that the predictors of T_IFET_4 explain 88.2 percent of its variance. In other words, the error variance between T_IFET_4 is approximately 11.8 percent of the variance between T_IFET_4 itself. Maximum likelihood estimates are also presented in Figure 2. 
Figure 2: SEM Graphs of Effectiveness of Teaching Economics

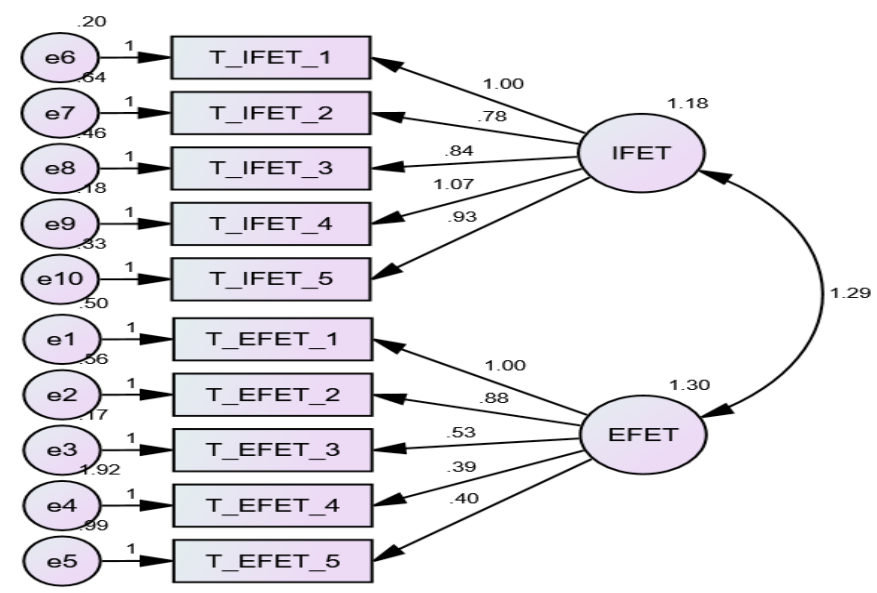

The standardized regression estimates are comparable, which may assist us to pick up more important factors and relationships which is presented in Table 5.

The variance between EFET is estimated to be 1.302. The variance estimate, 1.302, has a standard error of about 0.173 . Dividing the variance estimate by the estimate of its standard error gives $z=1.302 / .173=7.536$. In other words, the variance estimate is 7.536 standard errors above zero. The probability of getting a critical ratio as large as 7.536 in absolute value is less than 0.001. Likewise, the variance estimate for EFET is significantly different from zero at the 0.001 level (two-tailed).

Table 5: Variances and Squared Multiple Correlations

\begin{tabular}{lrrrrccc}
\hline & Estimate & S.E. & C.R. & P & Label & Squared Multiple Correlations \\
\hline EFET & 1.302 & .173 & 7.536 & $* * *$ & par_10 & Estimate & \\
IFET & 1.184 & .137 & 8.671 & $* * *$ & par_11 & & \\
e1 & .504 & .052 & 9.674 & $* * *$ & par_12 & T_IFET_5 & .758 \\
e2 & .565 & .056 & 10.017 & $* * *$ & par_13 & T_IFET_4 & .882 \\
e3 & .173 & .018 & 9.875 & $* * *$ & par_14 & T_IFET_3 & .642 \\
e4 & 1.921 & .190 & 10.114 & $* * *$ & par_15 & T_IFET_2 & .534 \\
e5 & .987 & .097 & 10.147 & $* * *$ & par_16 & T_IFET_1 & .856 \\
e6 & .199 & .024 & 8.345 & $* * *$ & par_17 & T_EFET_5 & .173 \\
e7 & .637 & .065 & 9.762 & $* * *$ & par_18 & T_EFET_4 & .094 \\
e8 & .462 & .048 & 9.580 & $* * *$ & par_19 & T_EFET_3 & .682 \\
e9 & .182 & .023 & 7.844 & $* * *$ & par_20 & T_EFET_2 & .642 \\
e10 & .330 & .036 & 9.198 & $* * *$ & par_21 & T_EFET_1 & .721 \\
\hline
\end{tabular}


The variance of IFET is estimated to be 1.184. The variance between estimates, 1.184, has a standard error of about.137. Dividing the variance estimate by the estimate of its standard error gives $\mathrm{z}=1.184 / .137=8.671$. In other words, the variance estimate is 8.671 standard errors above zero. The probability of getting a critical ratio as large as 8.671 in absolute value is less than 0.001 . In other words, the variance estimate for IFET is significantly different from zero at the 0.001 level (two-tailed). Likewise, the variance in e4 is estimated to be 1.921 . The variance between e 3 is estimated to be 0.173 . The variance in e7 is estimated to be 637 .

It is estimated that the predictors of T_IFET_ 5 explain 75.8 percent of its variance. In other words, the error variance in T_IFET_5 is approximately 24.2 percent of the variance between T_IFET_5 itself. It is estimated that the predictors of T_IFET_4 explain 88.2 percent of its variance. This means that, the error variance in T_IFET_4 is approximately 11.8 percent of the variance between T_IFET_4 itself. It is estimated that the predictors of T_IFET_1 explain 85.6 percent of its variance. In other words, the error variance in T_IFET_1 is approximately 14.4 percent of the variance between T_IFET_1 itself. It is estimated that the predictors of T_EFET_1 explain 72.1 percent of its variance. In other words, the error variance in T_EFET_1 is approximately 27.9 percent of the variance between T_EFET_1 itself.

The qualifiers of economics teachers (QOET) and availability of text materials on economics (ATME) are the influencing factors for learning economics to the higher secondary level students. To identify the influencing factors of the economics teacher psychometric scale, was designed and descriptive statistics are presented of the respondents specify their level of agreement or disagreement in Table 6.

There are ten statements and statements were divided into two group QOET and ATME factors that influencing teaching and learning economics in classroom for higher secondary level. Defined variables were Q_1 to and Q_5 and A_6 to A_10. The first statement was your teacher has the knowledge of mathematics in teaching economics. In this statement, the percentage of the mean was 64.57 and mode value was 4 . The statistics show that about only $65 \%$ respondents are agreed with the statement and 35 $\%$ data were error. This means that about $35 \%$ economics teachers have not a good knowledge of mathematics in teaching economics. 
Table 6: Descriptive Statistics of QOET and ATME Economics Learning

\begin{tabular}{llcccc}
\hline $\mathbf{N}$ & Variables & Mean & Mean \% & Mode & Std. Dev. \\
\hline 1Q & $\begin{array}{l}\text { Your teacher has the knowledge of } \\
\text { mathematics in teaching economics }\end{array}$ & 4.52 & 64.57 & 4 & 1.33 \\
2Q $\begin{array}{l}\text { The method of teaching used by your } \\
\text { teachers affects the learning of economics. }\end{array}$ & 6.14 & 87.71 & 7 & 0.82 \\
3Q $\quad \begin{array}{l}\text { Many of your economics teachers are degree } \\
\text { holders. }\end{array}$ & 6.76 & 96.57 & 7 & 0.68 \\
4Q $\begin{array}{l}\text { Teachers do not make use of appropriate } \\
\text { teaching materials. }\end{array}$ & $6 . .03$ & 86.14 & 7 & 1.28 \\
5Q $\quad \begin{array}{l}\text { Your teachers use of different teaching } \\
\text { method in the teaching of economics affect } \\
\text { your performance. }\end{array}$ & 6.09 & 87.00 & 7 & 1.16 \\
6A $\begin{array}{l}\text { The school libraries do not have current } \\
\text { economics textbooks. }\end{array}$ & 6.03 & 86.29 & 7 & 1.13 \\
7A $\begin{array}{l}\text { Poor preparation by teachers makes } \\
\text { economics learning uninteresting to students. }\end{array}$ & 6.16 & 88.00 & 7 & 0.99 \\
8A $\begin{array}{l}\text { Some students absent themselves from } \\
\text { economics class with hope to copy notes } \\
\text { from others and this affect their performance. }\end{array}$ & 6.24 & 89.14 & 7 & 0.77 \\
9A & $\begin{array}{l}\text { Majority of student's dislike economics } \\
\text { because of its mathematical involvement }\end{array}$ & 6.14 & 87.71 & 7 & 1.01 \\
10A $\begin{array}{l}\text { Employment of less qualified economics } \\
\text { teachers affects the students' interest in its } \\
\text { learning. }\end{array}$ & 6.04 & 86.29 & 7 & 1.61 \\
\hline
\end{tabular}

The minimum percentage of men for all variables were greater than 80 and the average mean $\%$ was 87.64 , and mode value for all variables was 7 except first variable. The average percent of statistics shows that about $88 \%$ students agreed the statement. That means, a method of teaching used by teachers affects the learning of economics. Likewise, teachers are highly qualified as higher secondary level, but teachers do not make use of appropriate teaching materials. Likewise, use of different teaching method to teach the economics, this affect teachers' performance. The data shows that, some school libraries do not have current economics textbooks. Present of teachers in classroom without preparation, it makes economics learning uninteresting. Students also agree with $8 \mathrm{~A}$ and 9A statement, which mean percentage were 89.14 and 87.71, so some students absent themselves from economics class with hope to copy notes from others and this affect their performance. Also, it is totally agreed that, majority of student's dislike economics because of its mathematical involvement. 
Table 7: Maximum Likelihood Estimates: Regression Weights

\begin{tabular}{|c|c|c|c|c|c|c|c|c|}
\hline & & & Estimate & S.E. & C.R. & $\mathbf{P}$ & Label & $\begin{array}{c}\text { Estimate } \\
\text { Standardized } \\
\text { Regression } \\
\text { Weights }\end{array}$ \\
\hline S_ATME_1 & $<-$ & ATME & 1.000 & & & & & .899 \\
\hline S_ATME_2 & $<-$ & ATME & .572 & .043 & 13.407 & $* * *$ & par_1 & .730 \\
\hline S_ATME_3 & $<-$ & ATME & .874 & .039 & 22.176 & $* * *$ & par_2 & .925 \\
\hline S_ATME_4 & $<-$ & ATME & .480 & .043 & 11.220 & $* * *$ & par_3 & .652 \\
\hline S_ATME_5 & $<-$ & ATME & .894 & .041 & 22.054 & $* * *$ & par_4 & .923 \\
\hline S_QOAT_1 & $<-$ & QOAT & 1.000 & & & & & .672 \\
\hline S_QOAT_2 & $<-$ & QOAT & .885 & .111 & 7.966 & $* * *$ & par_5 & .516 \\
\hline S_QOAT_3 & $<-$ & QOAT & .606 & .059 & 10.313 & $* * *$ & par_6 & .692 \\
\hline S_QOAT_4 & $<-$ & QOAT & .180 & .101 & 1.782 & .075 & par_7 & .109 \\
\hline S_QOAT_5 & $<-$ & QOAT & 1.236 & .101 & 12.254 & $* * *$ & par_8 & .853 \\
\hline
\end{tabular}

Maximum likelihood estimates at all the parameter estimates are actual significant. In other words, all the variables are significantly different from 0 except S_QOAT_4. The interpretations of the parameter estimate are straight forward. When ATME goes up by 1 , S_ATME_2 goes up by 0.572 .The regression weights to estimate, 0.572 , has a standard error of about 0.043 . Dividing the regression weight estimate by the estimate of its standard error gives $z=.572 / .043=13.407$. This indicates that, the regression weight estimate is 13.407 standard errors above zero. The probability of getting a critical ratio as large as 13.407 in absolute value is less than 0.001. In other words, the regression weight for ATME in the prediction of S_ATME_2 is significantly different from zero at the 0.001 level (two-tailed). When ATME goes up by 1 standard deviation, S_ATME_1 goes up by 0.899 standard deviations.

Analysis of next variable, if ATME goes up by 1, S_ATME_3 goes up by 0.874 . The regression weight estimate, .874 , has a standard error of about 0.039 . Dividing the regression weight estimate by the estimate of its standard error gives $\mathrm{z}=0.874 / 0.039=$ 22.176. The value indicates that, the regression weights to estimate is 22.176 standard errors above zero. The probability of getting a critical ratio as large as 22.176 in absolute value is less than 0.001. In other words, the regression weight for ATME in the prediction of S_ATME_3 is significantly different from zero at the 0.001 level (twotailed). When ATME goes up by 1 standard deviation, S_ATME_3 goes up by 0.925 standard deviations. 
The analysis of S_QOAT_5 to QOAT variables, When QOAT goes up by 1, S_QOAT_5 goes up by 1.236 . The regression weights to estimate, 1.236, has a standard error of about .101. Dividing the regression weight estimate by the estimate of its standard error gives $z=1.236 / 0.101=12.254$. That indicates, the regression weight estimate is 12.254 standard errors above zero. The probability of getting a critical ratio as large as 12.254 in absolute value is less than 0.001. In other words, the regression weight for QOAT in the prediction of S_QOAT_5 is significantly different from zero at the 0.001 level (two-tailed). When QOAT goes up by 1 standard deviation, S_QOAT_5 goes up by 0.853 standard deviations. Maximum likelihood estimates are also presented in Figure 3.

Figure 3: SEM Graphs of QOAT and ATME of Teachers

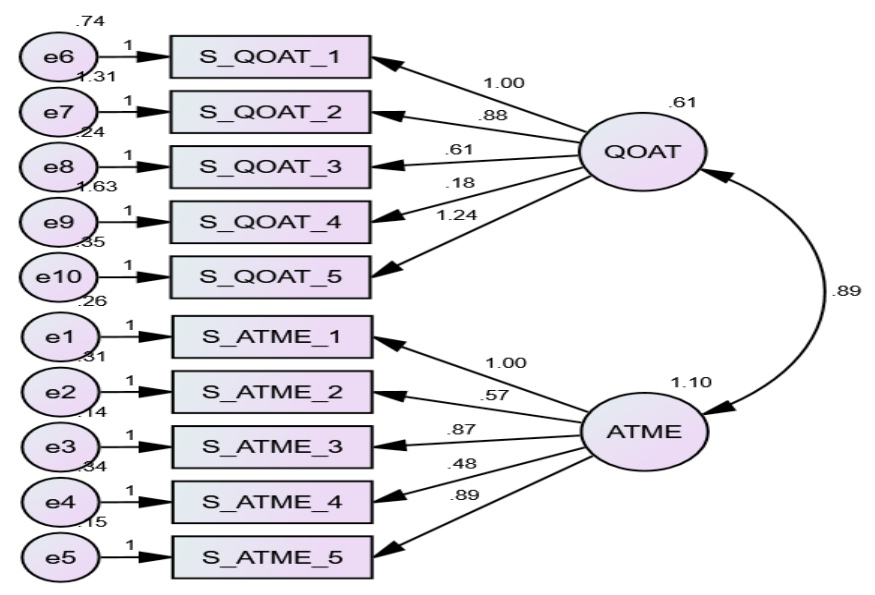

The standardized regression estimates are comparable, which may assist us to pick up more important factors and relationships which is presented in Table 8.

The variance between ATME is estimated to be 1.097. The variance estimate, 1.097, has a standard error of about 0.133 . Dividing the variance estimate by the estimate of its standard error gives $\mathrm{z}=1.097 / 0.133=8.263$. In other words, the variance estimate is 8.263 standard errors above zero. The probability of getting a critical ratio as large as 8.263 in absolute value is less than 0.001 . Which suggests that, the variance estimate for ATME is significantly different from zero at the 0.001 level (two-tailed). 
Table 8: Variances and Squared Multiple Correlations

\begin{tabular}{lrrrrrrr}
\hline & Estimate & S.E. & C.R. & P & Label & \multicolumn{2}{c}{ Squared Multiple Correlations } \\
ATME & 1.097 & .133 & 8.263 & $* * *$ & par_10 & & \\
QOAT & .606 & .108 & 5.631 & $* * *$ & par_11 & Estimate & \\
e1 & .262 & .028 & 9.336 & $* * *$ & par_12 & S_QOAT_5 & .728 \\
e2 & .315 & .032 & 9.915 & $* * *$ & par_13 & S_QOAT_4 & .012 \\
e3 & .141 & .016 & 8.907 & $* * *$ & par_14 & S_QOAT_3 & .479 \\
e4 & .342 & .034 & 9.975 & $* * *$ & par_15 & S_QOAT_2 & .266 \\
e5 & .151 & .017 & 8.948 & $* * *$ & par_16 & S_QOAT_1 & .452 \\
e6 & .735 & .067 & 10.942 & $* * *$ & par_17 & S_ATME_5 & .853 \\
e7 & 1.309 & .122 & 10.695 & $* * *$ & par_18 & S_ATME_4 & .425 \\
e8 & .242 & .022 & 10.947 & $* * *$ & par_19 & S_ATME_3 & .856 \\
e9 & 1.631 & .161 & 10.104 & $* * *$ & par_20 & S_ATME_2 & .533 \\
e10 & .346 & .034 & 10.306 & $* * *$ & par_21 & S_ATME_1 & .807 \\
\hline
\end{tabular}

The predicated of variance QOAT is to 0.606 . The variance estimate, 0.606 , has a standard error of about .108. Dividing the variance estimate by the estimate of its standard error gives $z=0.606 / 0.108=5.631$. In other words, the variance estimate is 5.631 standard errors above zero. The probability of getting a critical ratio as large as 5.631 in absolute value is less than 0.001 . Which means that, the variance estimate for QOAT is significantly different from zero at the 0.001 level (two-tailed).The variance between e1 is estimated to be 0.262 . The variance estimate, 0.262 , has a standard error of about .028. Dividing the variance estimate by the estimate of its standard error gives $z=0.262 / 0.028=9.336$. In other words, the variance estimate is 9.336 standard errors above zero. The probability of getting a critical ratio as large as 9.336 in absolute value is less than 0.001 . Thus, the variance estimate for $\mathrm{e} 1$ is significantly different from zero at the 0.001 level (two-tailed). It is estimated that the predictors of S_QOAT_1 explain 45.2 percent of its variance. In other words, the error variance between S_QOAT_1 is approximately 54.8 percent of the variance in S_QOAT_1 itself.

The variance at e 6 is estimated to be 0.735 . The variance estimate, 0.735 , has a standard error of about .067. Dividing the variance estimate by the estimate of its standard error gives $\mathrm{z}=0.735 / 0.067=10.942$. The viewpoint is that, the variance estimate is 10.942 standard errors above zero. The probability of getting a critical ratio as large as 10.942 in absolute value is less than 0.001 . The estimation indicates that, the variance estimate for e6 is significantly different from zero at the 0.001 level (two-tailed). It is estimated that the predictors of S_ATME_1 explain 80.7 percent of its variance and the error variance between S_ATME_1 is approximately 19.3 percent of the variance between S_ATME_1 itself. 
Maximum likelihood estimates at latent variable, endogenous and exogenous variable and find out the relation between gender, age and teaching experience and their effectiveness of economics teaching in classroom for higher secondary school level. In Table 9, the statistical results of maximum likelihood estimate are presented.

Table 9: Maximum Likelihood Estimates and Standardized Regression Weights of Latent Endogenousand Exogenous Variables

\begin{tabular}{|c|c|c|c|c|c|c|c|c|}
\hline & & & Estimate & S.E. & C.R. & $\mathbf{P}$ & Label & Estimate \\
\hline Age & $<-$ & Gender & -.034 & .226 & -.151 & .880 & par_1 & -.011 \\
\hline Experience & $<-$ & Gender & .002 & .214 & .008 & .994 & par_2 & .001 \\
\hline S_QOAT_2 & $<-$ & Experience & .076 & .084 & .911 & .362 & par_3 & .059 \\
\hline S_QOAT_4 & $<-$ & Experience & .250 & .084 & 2.967 & .003 & par_4 & .198 \\
\hline S_QOAT_1 & $<-$ & Age & -.225 & .071 & -3.176 & .001 & par_5 & -.217 \\
\hline S_QOAT_3 & $<-$ & Age & -.127 & .042 & -3.008 & .003 & par_6 & -.207 \\
\hline S_QOAT_4 & $<-$ & Age & -.287 & .080 & -3.591 & $* * *$ & par_7 & -.240 \\
\hline S_QOAT_5 & $<-$ & Age & -.234 & .070 & -3.328 & $* * *$ & par_8 & -.227 \\
\hline S_QOAT_5 & $<-$ & Experience & .079 & .074 & 1.068 & .286 & par_9 & .073 \\
\hline S_QOAT_1 & $<-$ & Experience & -.064 & .075 & -.860 & .390 & par_10 & -.059 \\
\hline S_QOAT_2 & $<-$ & Age & -.456 & .080 & -5.735 & $* * *$ & par_11 & -.373 \\
\hline S_QOAT_3 & $<-$ & Experience & -.012 & .044 & -.278 & .781 & par_12 & -.019 \\
\hline
\end{tabular}

The regression weights to estimate, -0.034 , has a standard error of about 0.226 . Dividing the regression weight estimate by the estimate of its standard error gives $\mathrm{z}=$ $-0.034 / .226=-0.151$. The regression weights to estimate is 0.151 standard errors below zero. The probability of getting a critical ratio as large as $0.151 \mathrm{in}$ absolute value is .880 . The regression weight for gender in the prediction of Age is not significantly different from zero at the 0.05 level (two-tailed). When gender goes up by 1 standard deviation, age goes down by 0.011 standard deviations.

The analysis of the relation between gender and experience, when gender goes up by 1 , Experience goes up by 0.002 . The regression weights to estimate, 0.002 , has a standard error of about .214. Dividing the regression weights to estimate by the estimate of its standard error gives $z=0.002 / .214=0.008$. In other words, the regression weights to estimate is 0.008 standard errors above zero. The probability of getting a critical ratio as large as 0.008 in absolute value is 0.994 . The regression weight for Gender in the prediction of Experience is not significantly different from zero at the 0.05 level (twotailed). 
When experience goes up by 1, S_QOAT_4 goes up by 0.25 . The regression weight estimate, 0.250 , has a standard error of about 0.084 . Dividing the regression weight estimate by the estimate of its standard error gives $z=0.250 / 0.084=2.967$. Further difference between opinion, the regression weight estimate is 2.967 standard errors above zero. The probability of getting a critical ratio as large as 2.967 in absolute value is 0.003 . The regression weight for Experience in the prediction of S_QOAT_4 is significantly different from zero at the 0.01 level (two-tailed). When Experience goes up by 1 standard deviation, S_QOAT_4 goes up by 0.198 standard deviations.

When age goes up by 1, S_QOAT_4 goes down by 0.287 . The regression weights to estimate, -0.287 , has a standard error of about 0.080 . Dividing the regression weight estimate by the estimate of its standard error gives $z=-0.287 / 0.080=-3.591$. The result of, regression weight estimate is 3.591 standard errors below zero. The probability of getting a critical ratio as large as 3.591 in absolute value is less than 0.001 . In addition, the regression weight for Age in the prediction of S_QOAT_4 is significantly different from zero at the 0.001 level (two-tailed).

In Table 10 variance between gender and its statistical results are presented. The variance between gender is estimated to be 0.118 .The variance estimate, 0.118 , has a standard error of about 0.012 . Dividing the variance estimate by the estimate of its standard error gives $\mathrm{z}=0.118 / 0.012=10.075$. Furthermore, the variance estimate is 10.075 standard errors above zero. The probability of getting a critical ratio as large as 10.075 in absolute value is less than 0.001 . In other words, the variance estimate for gender is significantly different from zero at the 0.001 level (two-tailed). In figure 3 presenting the graphs of the SEM of age, gender and experience in teachers influence to students learning economics in higher secondary school level.

Table 10: Variances and Squared Multiple Correlations

\begin{tabular}{|c|c|c|c|c|c|c|c|}
\hline & Estimate & S.E. & C.R. & $\mathbf{P}$ & Label & & Estimate \\
\hline Gender & .118 & .012 & 10.075 & $* * *$ & par_13 & & \\
\hline e1 & 1.224 & .122 & 10.075 & $* * *$ & par_14 & Experience & .000 \\
\hline e2 & 1.105 & .110 & 10.075 & $* * *$ & par_15 & Age & .000 \\
\hline e3 & 1.253 & .124 & 10.075 & $* * *$ & par_16 & S_QOAT_5 & .057 \\
\hline e4 & 1.575 & .156 & 10.075 & $* * *$ & par_17 & S_QOAT_4 & .097 \\
\hline e5 & .442 & .044 & 10.075 & $* * *$ & par_18 & S_QOAT_3 & .043 \\
\hline e6 & 1.589 & .158 & 10.075 & $* * *$ & par_19 & S_QOAT_2 & .142 \\
\hline e7 & 1.227 & .122 & 10.075 & $* * *$ & par_20 & S_QOAT_1 & .051 \\
\hline
\end{tabular}


The variance between $\mathrm{e} 1$ is estimated to be 1.224 . The variance estimate, 1.224, has a standard error of about.122. Dividing the variance estimate by the estimate of its standard error gives $\mathrm{z}=1.224 / 0.122=10.075$. Moreover, the variance estimate is 10.075 standard errors above zero. The probability of getting a critical ratio as large as 10.075 in absolute value is less than 0.001 . The variance estimate for $\mathrm{e} 1$ is significantly different from zero at the 0.001 level (two-tailed). The variance between e6 is estimated to be 1.589. The variance estimate, 1.589 , has a standard error of about 0.158 . Dividing the variance estimate by the estimate of its standard error gives $z=1.589 / 0.158=10.075$. This indicates that, the variance estimate is 10.075 standard errors above zero. The probability of getting a critical ratio as large as 10.075 in absolute value is less than 0.001 . In additional arguments, the variance estimate for e6 is significantly different from zero at the 0.001 level (two-tailed).

\section{Figure 4: SEM Graph among Age, Gender and Experience of Teachers relation to Students}

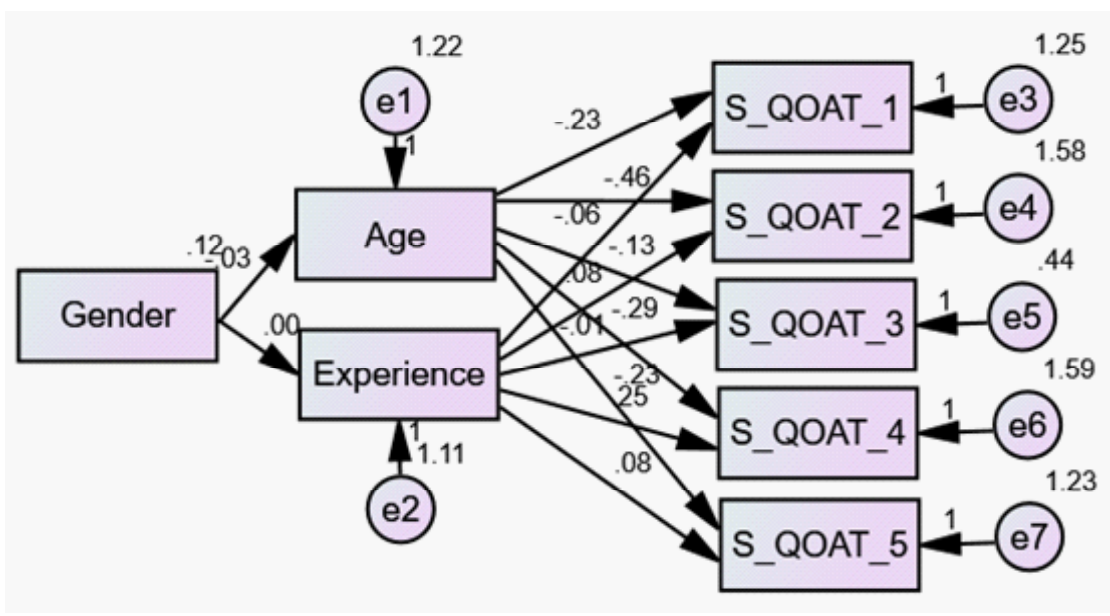

It is estimated that the predictors of experience explain 0 percent of its variance. This indicates that the error variance in experience is approximately 100 percent of the variance between experiencing itself. The predictors of age explain 0 percent of its variance. In the calculation, the error variance between age is approximately 100 percent of the variance in Age itself. The predictors of S_QOAT_5 explain 5.7 percent of its variance, the error variance between S_QOAT_5 is approximately 94.3 percent of the variance in S_QOAT_5 itself. The predictors of S_QOAT_4 explain 9.7 percent of its variance or the error variance between S_QOAT_4 is approximately 90.3 percent of the variance in S_QOAT_4 itself. Likewise, it is estimated that the predictors of S_ 
QOAT_3 explain 4.3 percent of its variance or, the error variance between S_QOAT_3 is approximately 95.7 percent of the variance in S_QOAT_3 itself. The estimation of the predictors of S_QOAT_2 explains 14.2 percent of its variance or the error variance between S_QOAT_2 is approximately 85.8 percent of the variance in S_QOAT_2 itself. The estimated predictors of S_QOAT_1 explain 5.1 percent of its variance and, the error variance between S_QOAT_1 is approximately 94.9 percent of the variance in S_QOAT_1 itself.

\section{CONCLUSION}

The research findings specify that the nonexistence of classroom spaced in the school, given time to the teaching of economics teachers with a new technology, unavailability of recent economics textbooks, systematic libraries and computer facilities, influences the teaching performance. Training with new teaching andragogy with computer application facilitated to economics teacher improved teachers' qualities and better teaching economics in the classroom, which vary the most important factors that affect teaching economics. Likewise, appoint highly qualified teachers for higher secondary level, administration to teachers do make use of appropriate teaching materials and also encourage use of different teaching method in the teaching of economics that affect teaching performance. According to the age, gender and experiences do not exist the teaching and learning economics, but knowledge of teacher and preparation for class lecture and other activities can give the interest in economics class. Application of mathematics in economics with real data onto microeconomics, an example demand analysis of the local market, GDP data can be analyzed in macroeconomics. Time and again teachers' training to play the important role to better teach economics in higher secondary school levels in Nepal. This is recommended that teach the teachers as a workshop style training as improving economics instruction in higher secondary school level. The experimental program helps teachers to gain an understanding of economic concepts and to improve andragogy-pedagogy. Improved classroom environment, the latest text materials might be the encouraging to economics subject to the student. And also, recommended two types of tanning pre-service training for new teachers, and inservice training for those teachers who are already teaching. Both are essential ways for improving the prospects of imbuing economics in other subject areas.

\section{Acknowledgement}

The author warmly acknowledges the kind cooperation extended by Mr. Dhal B. Khadka (the then joint secretary of HSEB) and respected professors Dr. Parthiveshwor P. Timilshina and Dr. Keshav R. Khadka, along with other resource persons Dr. Chakra P. Luitel, Mr. Binod Joshi, Ms. Indira Shrestha, Mr. Madhav P. Dahal, Nar B. Bista, and Mr. Tara P. Bhusal who accompanied with the author in the training cum workshop organized by HSEB(the then) and shared their ideas and experienceon several issues of teaching economics. 


\section{References}

Adu, E.O., Galloway, G., \& Olaoye, O. (2014). Teachers' characteristics and students' attitude towards economics in secondary schools: Students' perspectives. Mediterranean Journal of Social Sciences, 5(16), 455-462.

Bentler, P. M., \& Bonett, D. G. (1980). Significance test and goodness of fit in the analysis of covariance structures. Psychological Bulletin, 88, 588-606.

Blazar, D. (2015). Effectiveness teaching in elementary mathematics: Identifying classroom practices that support student achievement. Economics of Education Review, 48, 16-29. Retrieved from www.elsevier.com/locate/econedurev.

Bollen, K. A., \& Joreskog, K. G. (1985). Uniqueness does not imply identification: A note on confirmatory factor analysis. Sociological Methods and Research, 14, 155163.

Browne, M. W. (1984). Asymptotically distribution-free methods for the analysis of covariance structures. British Journal of Mathematical and Statistical Psychology, 37, 1-21. http://www2.gsu.edu/ mkteer/discrep.html\#refs.

Byrne, B. M. (2001). Structural equation modeling with AMOS: Basic concepts, applications and programming. Mahwah, NJ: Erlbaum.

Chamberlain, G. (1982). Multivariate regression models for panel data. . Journal of Econometrics, 18(1), 5-46. Retrieved fromhttp://www.sciencedirect.com/ science/article/pii/0304-4076 (82)90094-X.

Chibueze, O. (2014). Factors affecting the effective studying of economics in secondary schools in Izzi Local Government Area of Ebonyi State. National Teachers Institute Ebonyi State University Study Centre, Abakaliki. Retrieved fromhttps://www. academia.edu/10115175.

Cronbach, L. J. (1951). Coefficient alpha and the internal structure of tests. Psychometrika, 16, 297-334. Retrieved from: http://kttm.hoasen.edu.vn/sites/ default/files/2011/12/22/cronbach_1951_coefficient_alpha.pdf.

European Commission. (2008). Handbook on constructing composite indicators methodology and user guide. European Commission. Retrieved from https://www.oecd.org/ std/42495745.pdf.

Higher Secondary Education Board(2006). Teacher training manual: Economics. Higher Secondary Education Board Curriculum and Training Division. Sanothimi, Bhaktapur: Author 
Hooper, D. C., Coughlan, J., \& Mullen, M. (2008). Structural equation modeling: Guidelines for determining model fit. Electronic Journal of Business Research Methods, 6(1), 53-60.Retrieved from http://arrow.dit.ie/buschmanart.

Hox, J. J. \& Bechger, T. M. (2011). An introduction to structural equation modeling. Family Science Review, 11, 354-373.

Idoko, C. U.\& Emmanuel, A.(2015). (2015). Teachers effectiveness in teaching economics: Implication for secondary education. International Journal of Innovative Research E Development, 4(2), 69-72.

Izci, K. (2016). Internal and external factors affecting teachers' adoption of formative assessment to support learning. International Journal of Social, Behavioral, Educational, Economic, Business and Industrial Engineering, 10(8), 2541-2548.

Joreskog, K. G. and Sorbom, D. (1982). Recent developments in structural equation modeling. Journal of Marketing Research, 19(000004), 404-416. Retrieved from http://personal.psc.isr.umich.edu/yuxie-web/files/pubs/Articles/Joreskog_ Sorbom1982.pdf.

Keynes, J. N. (1890). The scope and method of political economy (4th ed.), On the character and definition of political economy regarded as a political science (P. 44, 100). Canada: Batoche Books Kitchener.

--The scope and method of political economy $\left(4^{\text {th }}\right.$ ed. $)$, On the deductive method in political economy. Canada:Batoche Books Kitchener.

Kline, R. B. (2005). Principles and practice of structural equation modeling (2nd ed.). New York: The Guildford Press.

Kullback, S. \&. (1951). On information and sufficiency. Annals of Mathematical Statistics, 22, 79-86.

Loehlin, J. C. (1992). Latent variable models: An introduction to factor, path, and structural analysis (2nd ed.). Mahwah, New Jersey: Lawrence Erlbaum Associates.

McConnell, C. R., Brue, S. L., \& Flynn, S. M. (2009). Economics: Principles, problems, and policies (18th ed.). McGraw-Hill/Irwin, a business unit of The McGraw-Hill Companies, Inc., 1221, Avenue of the Americas, New York.

National Council of Educational and Training (2005). Teaching economics in India: A teacher's handbook. Department of Education in Social Sciences, National Council of Educational Research and Training, Sri Aurobindo Marg, New Delhi, India: Author. 
O'Sullivan, A. \& Sheffrin, S. M. (2003). Macroeconomics principles and tools (3rd Ed.). Pearson Education Inc., Upper Saddle River, New Jersey, United States of America.

Robbins, L. (1935). An essay on the nature and significance of economic science. MacMillan and Co. London, United Kingdom.

Robertson, C., \& Acklam, R. (2000). Action plan for teachers a guide to teaching English. Edited by: Tim Moock, British Broadcasting Corporation. Retrieved from www.bbc.co.uk/worldservice/learningenglish.

Smirnova, N. V. (2016). Economics across the curriculum: integration of economic concepts into various disciplines. Perspectives on Economic Education Research, American Institute for Economic Research, , 10(1), 21-40. Retrieved fromhttp:// cobhomepages.cob.isu.edu/peer/links/volumes/10.1/Smirnova.pdf.

Tucker, L. R. \& Lewis, C. (1973). A reliability coefficient for maximum likelihood factor analysis. Psychometrika, 38, 1-10.

Vasiliki, B., Panagiota, K., \& Maria, S. K. (2016). A new teaching method for teaching economics in secondary education. Journal of Research \& Method in Education, 6(2), 86-93. 